\title{
Analysis of Tropical Cyclones in the South China Sea and Bay of Bengal during Monsoon Season
}

\author{
Lei Yang ${ }^{1}$, Wei-Wei Li ${ }^{1}$, Dongxiao Wang ${ }^{1}$ and Yongping $\mathrm{Li}^{2}$ \\ ${ }_{1}^{1}$ Key Laboratory of Tropical Marine Environmental Dynamics, \\ The South China Sea Institute of Oceanology, Chinese Academy of Science, Guangzhou, \\ ${ }^{2}$ Shanghai Typhoon Institute, China Meteorological Administration, Shanghai,
}

China

\section{Introduction}

Using reanalysis and satellite data sets, numerical simulation and statistical methods are applied for investigating tropical cyclone (TC) of two ocean basins: the South China Sea (SCS) and Bay of Bengal (BOB). Influenced by Asian monsoon, TCs' feature in these two ocean basins differ from the one of other open oceans. In this chapter, a unique TC case passing through SCS as well as TCs track characteristics in BOB are examined.

The Fifth Pennsylvania State University and National Center for Atmospheric Research Mesoscale Model (MM5) is utilized to study the precipitation and wind speed during Typhoon Chanchu (2006) in SCS. Five model experiments with different physical parameterizations and sea surface temperature (SST) distributions are carried out in the study. Simulations are evaluated using satellite observations. It is found that the control experiment that is configured with the Blakadar boundary scheme, Resiner2 moisture, the Betts-Miller cumulus scheme and daily updated SST has the most reasonable precipitation. The MRF boundary scheme tends to simulate a dryer boundary layer and stronger vertical mixing, which can greatly reduce the intensity of tropical cyclone (TC), resulting in smaller maximum wind speed but larger range of medium wind speed $(25-30 \mathrm{~m} / \mathrm{s})$. Constant SST through the TC cycle provides more energy from ocean surface, which could cause a significant increase in TC's intensity and therefore result in the largest overestimation on rainfall and maximum wind speed. Longitudinally-uniform SST distribution before the rapid intensification could reduce TC's intensity and heat fluxes, which can partially compensate for the overestimation of precipitation in the control experiment.

Based on a mixture quadratic regression model and the best track dataset 1980-2008, six distinct clusters of TC tracks in the Bay of Bengal (BOB) were identified. For better capturing the background controlling factors, reclassifying is carried out by treating all westward tracks as one type. Thereafter, three track types are obtained, northeastward (fewest in amount), westward (most in amount), and northward. Seasonal variability indicates that northward track type should be divided by two stages (April-May and October-January). After examining the background circulation of each track type, it is found that except for the northeastward one, anticyclonic circulation located in Indo-China Peninsular as well as 
trough activity in the region of India-Burma played important roles on modulating local wind. These systems assisted steering TC passing through this region. In addition, TCs happened in April and May (pre-summer-monsoon), generally were prone to be affected by the cross-equatorial-flow and move northward.

Results will be given in the following two sections: "South China Sea: Wind and precipitation pattern during typhoon Chanchu (2006) - Comparison between a mesoscale model and remote sensing" and "Bay of Bengal: Cluster Analysis of Tropical Cyclone Tracks”.

\section{South China Sea: wind and precipitation pattern during Typhoon Chanchu (2006) - Comparison between a mesoscale model and remote sensing}

\subsection{Introduction}

Tropical cyclones (TCs) are one of the most deadly nature hazards to the coastal areas, causing large amounts of casualties and property losses. The South China Sea (SCS) is the largest semi-enclosed marginal sea $(\sim 3.5 \times 106 \mathrm{~km} 2)$ in the Northwest Pacific Ocean (WNP), the region of most frequent TC formation in the earth. About $13.2 \%$ of TCs in the WNP originates from the SCS (Chen and Ding, 1979). Certain amounts of TCs generated in the WNP also enter the SCS with large inter-annual and decadal variability (Goh and Chan, 2009).

How ever, compared to the TCs over other ocean basins, there are relatively fewer studies in the literature on TC formation and development over the SCS. The numbers of TCs entering the SCS from the WNP are found below normal during El Nino events, but above normal during La Nina events (Goh and Chan, 2009). It is more complicated for the interannual and decadal variability of the TCs formed in the SCS. The significant atmospheric characteristic in the SCS is that it experiences winter and summer monsoon every year (Liang, 1991). The onset of summer monsoon in the SCS usually starts during mid-May and maintains until September. It is found that during summer (winter) monsoon period, TCs are mainly formed in the northern (southern) part of the SCS (e.g., Wang et al., 2007). The TC activity in the SCS correlates well with the sea surface temperature (SST) and outgoing longwave radiation (OLR) variation (Lee et al., 2006). The formation region of the TCs corresponds with the area where relative vorticity of surface wind (RVSW) is positive, i.e., almost no TCs formed in the negative RVSW area (Lee et al., 2006; Wang et al., 2007). Lee et al. (2006) examined 20 TCs in the SCS during 1972-2002 (May-June), 11 of which are associated with weak baroclinic environment of a mei-yu front and rest of which are more barotopic and possibly intensifies into a stronger TC. The Columnar water vapor, columnar liquid water and the total latent heat release derived from the Special Sensor Microwave/ Imager (SSM/ I) are found to have significant different in the developing and non-developing tropical disturbances in the SCS (Wang et al., 2008).

The studies of TCs in the SCS, in terms of model simulations and evaluations, are even less. Numerical model simulation can help us to better understand the dynamics of a TC process and therefore help to improve TC forecast skill. Observational data, such as sounding data, Argo floats, satellite data and others have been widely used to improve model simulation (e.g. Soden et al., 2001; Zhao et al., 2005; Chou et al., 2008; Langland et al., 2009; Rakesh et al., 2009). Besides incorporating observations in the simulation to improve forecast skill, evaluation or validation of a model simulation is also possible by comparing the simulations with observational data (e.g. Li et al., 2008; Nolan et al., 2009; Zou et al., 2009). Several 
simulation studies have been done for the TCs in the SCS. Typhoon Leo (1999) was successfully simulated using two nested domains in relatively coarse resolution ( $54 \mathrm{~km}$ and $18 \mathrm{~km}$ ) (Lau et al., 2003). The Fifth Pennsylvania State University and National Center for Atmospheric Research Mesoscale Model (MM5) was applied to simulate several characteristics of Typhoon Fitow (2001), including land falling, center position, and precipitation ( $\mathrm{Li}$ et al., 2004). SST effects on the simulation of the genesis of Typhoon Durian (2001) were investigated using the Weather Research and Forecasting (WRF) model (Wang et al., 2010). MM5 incorporating 4D variational data assimilation system with a full-physics adjoint model was found to greatly improve typhoon forecast in track, intensity, and landfall position (Zhao et al., 2005) .

In this study, we mainly discuss the simulated precipitation and wind pattern during the case of Typhoon Chanchu (2006) using MM5. Previous studies on Typhoon Chanchu (2006) in the SCS mainly focused on analyzing its track and intensity using National Centers for Environmental Prediction (NCEP)/ NCAR reanalysis data (Luo et al., 2008). Except for the impact of meteorological factors, ocean effect such as sea surface temperature (SST) on the TC's development has also been studied (Jiang et al., 2008). It is found that considering typhoon-induced cooling in the model simulation can greatly improve the simulation skill of the TC's intensity. Sensitive studies with different SST configurations in Weather Research and Forecasting (WRF) showed that SST variation could cause change in TC's intensity and slightly affect its track as well (Liu et al., 2009).

\subsection{Overview of Chanchu (2006)}

Typhoon Chanchu (2006) is the first tropical storm in 2006, with a maximum sustained wind speed reaching $46 \mathrm{~m} / \mathrm{s}$ near its centre during the rapid intensification (RI) on 15 May 2006 in the SCS. It is the most intense typhoon on the Hong Kong Observatory (HKO) record to enter the SCS in May. The TC was originated at the south Philippine Sea on 8 May 2006, when it was declared as a tropical depression. It later strengthened into a typhoon and struck the Philippines twice. It entered the SCS on 13 May 2006 and rapidly intensified into Category 4 (in Saffir-Simpson tropical cyclone scale) on 14 May 2006. During its passage over the SCS, it moved to NW first and turned sharply to NNE while it made its final landfall near Shantou in eastern Guangdong Province, China.

\subsection{Model}

MM5 is a non-hydrostatic, primitive equation model with a terrain-following sigmacoordinate (Grell et al. 1995). Model simulations of a TC process can vary with many factors, such as model physical parameters, ocean conditions, topography, among others. A total of five experiments are performed to test model sensitivities to some of the above-mentioned factors. All the model runs are initiated at 00 UTC 12 May when the storm was about to enter the SCS. The model version has a horizontal resolution of $15 \mathrm{~km}$ and $5 \mathrm{~km}$ for Domain 1 and Domain 2, respectively, and 27 vertical levels. Blackdar PBL, Resiner2 moisture and the Betts-Miller cumulus scheme are used in the CTL. Other four experiments are named as PBL_MRF (using MRF PBL), CUM_G (using the Grell cumulus scheme), SST_C (constant SST distribution during TC process, i.e., ignoring the TC induced ocean cooling) and SST_U (longitudinally-uniform SST distribution in the central SCS before the RI).

NCEP Final Analysis (FNL) 6-hourly data are used for the initial and boundary conditions. SST is updated daily with real-time, global SST (RTG_SST) developed at the NCEP/ Marine 
Modeling and Analysis Branch (MMAB) to represent storm-induced SST changes during the life-cycle of a typhoon. The data has a spatial resolution of $0.5^{\circ}$. Although it is more desirable to use a coupled ocean model to represent storm-induced SST changes with a high resolution, our simulations should have smaller SST errors than those from a coupled model due to technique issues. Regular sounding and synoptic observations were used to refine the NCEP FNL analysis data before the simulations start. Wind bogus is inserted for better results of initial vortex (Zou and Xu 2000). Corresponding winds and locations are obtained from the Joint Typhoon Warning Center (JIWC) of the U.S.

\subsection{Data}

\subsubsection{TRMM}

Three-hourly merged rain rate from the Tropical Rainfall Measuring Mission (TRMM) satellite's Precipitation Radar (PR) is used in this study to evaluate the simulations. The PR is a three-dimensional space-borne precipitation radar that, at its nadir point, has horizontal and vertical resolutions of 4.3 by $4.3 \mathrm{~km}$ and $250 \mathrm{~m}$, respectively. The PR retrieves reflectivities at a frequency of $13.8 \mathrm{GHz}$ from the surface to $20 \mathrm{~km}$ above the Earth ellipsoid. It has a $215-\mathrm{km}$ swath width with a minimum detectable signal of nearly $17 \mathrm{dBZ}$. The $3-$ hourly rainfall data has a horizontal resolution of $0.25^{\circ}$ by $0.25^{\circ}$, and extends from January 1998 to June 2006 . The 3 -hourly rain rate is then used to calculate 24 -houlyr accumulated rainfall in this study.

\subsubsection{QuikSCAT}

The SeaWinds scatterometer on the QuikSCAT is a microwave radar launched and operated by the U.S. National Aeronautics and Space Administration (NASA) from July 1999 to November 2009. The QuikSCAT measures the back scatter radiation in the Ku-band ( 13.402 $\mathrm{GHz}$ ). The return signal power is proportional to surface stress over the ocean, and the signal can be related to surface wind vector at $10 \mathrm{~m}$ height assuming neutral stratification. In addition to wind vector data, the times (minutes of UTC) of measurements are also provided. The data are regridded to $0.25^{\circ}$ by $0.25^{\circ}$ (latitude by longitude) map for ascending and descending passes. In order to make a better comparison, we choose the model hours that are the closest to the time when the satellite passes the SCS.

\subsection{Comparisons between model-simulated and TRMM-derived precipitations}

The spatial patterns of 24-hour-accumulated precipitation are shown for three days: 14, 15, and 17 May 2006, which represent before, during and after the RI, respectively. Figure 1 shows 24-hour-accumulated precipitation during the three days simulated by the CTL and derived from TRMM measurements. CTL simulates overall larger rainfall than TRMM, especially in the area surrounding the storm center. The difference in main rainfall area is obviously due to the faster translation speed simulated by CTL, i.e., more northward in CTL than in TRMM. In addition, the rainfall patterns simulated by CTL have more compact structure and clearer spiral rainbands. The maximum accumulated rainfall in CTL is clearly larger than the TRMM measurement, with the largest difference during the RI period. Large rainfall area in the model simulation is mainly located at the center before and after the RI (not shown), but at west or northwest of the rainfall area during the RI period (Fig. 2). After the RI, the TC moves closer to the coast; the formation of maximum rainfall should be related to coastal-enhanced mechanism, which seems much stronger in the model 


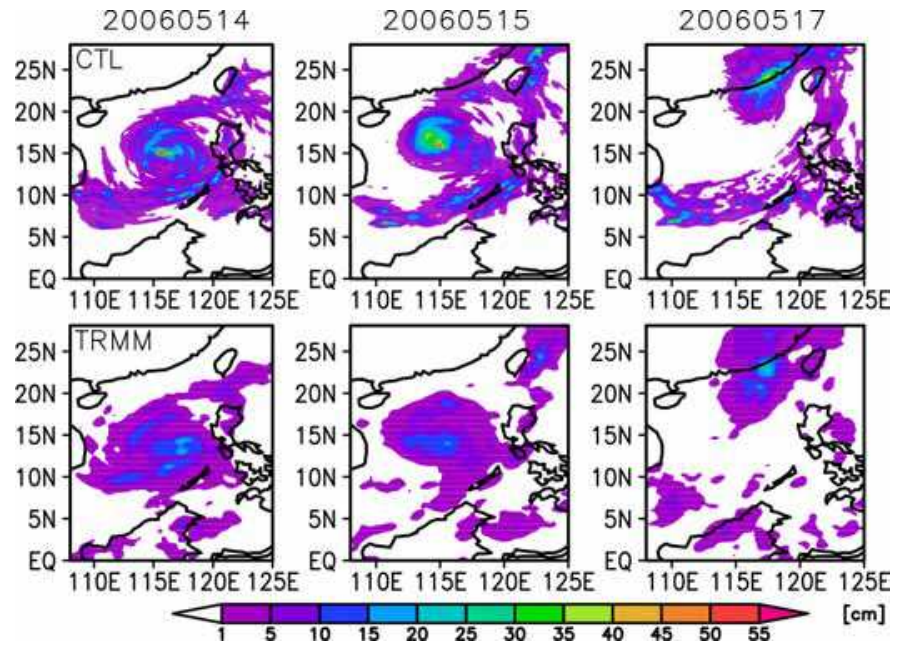

Fig. 1. Comparison of 24-hour-accumulated precipitation derived from CTL (top) and TRMM PR (bottom) during the three days.
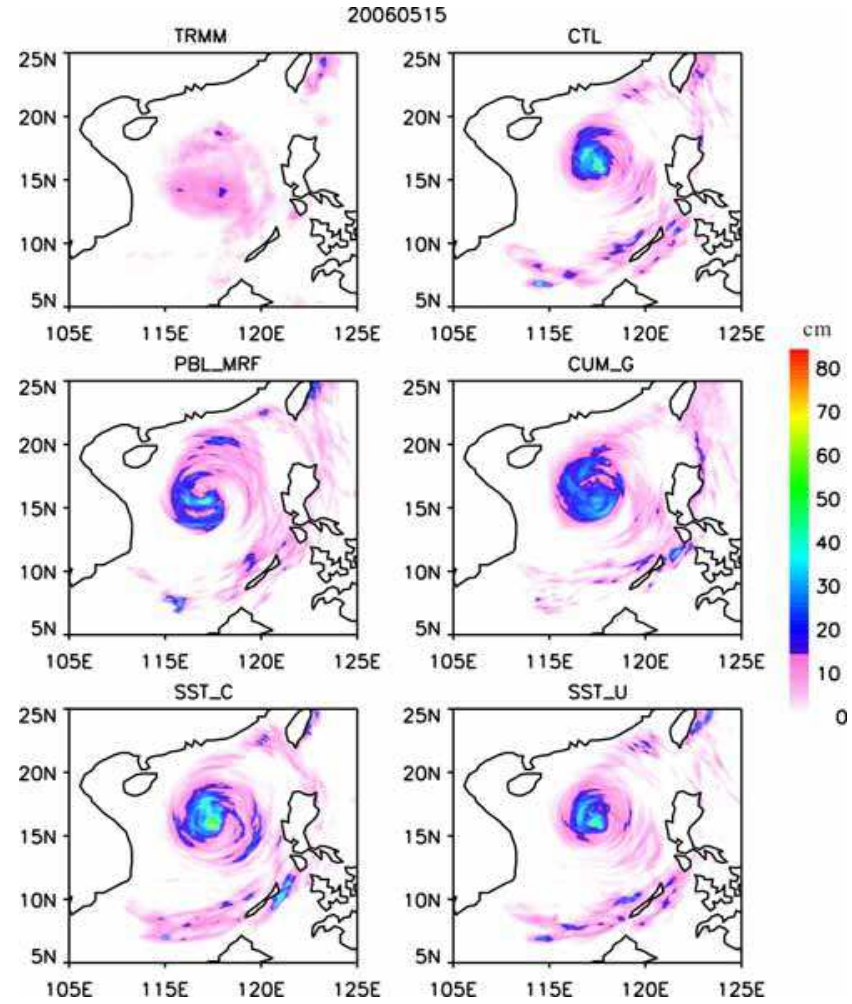

Fig. 2. Comparison of 24-hour-accumulated precipitation derived from TRMM PR and the five model simulations on 15 May 2006 (the RI period). 

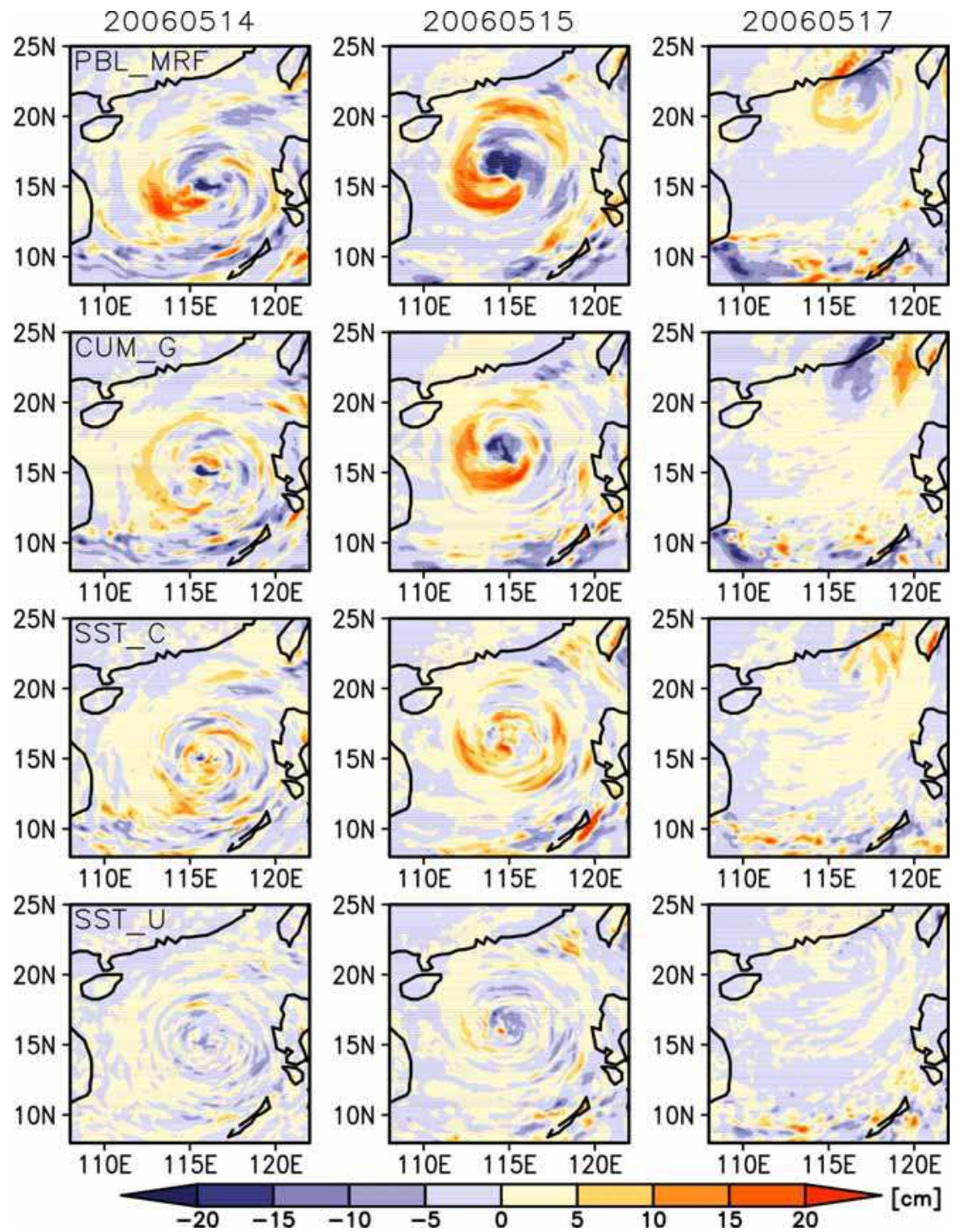

Fig. 3. Differences in simulated 24-hour-accumulated precipitation during the three days: sensitive run minus CTL.

simulation. TRMM gives larger range of the rainfall but weaker strength. The differences of the large rainfall area location between the sensitive runs and CTL can be clearly seen in Fig. 3 , in which rainfall simulated by the four sensitive runs are compared with CTL.

The differences between the four sensitivity runs and CTL for the three days are illustrated in Fig. 3. Though having a dryer PBL, PBL_MRF tends to simulate a deeper PBL due to excessive vertical mixing outside of the eye wall (Hong and Pan 1996), which could lead to the overall heavy precipitation in PBL_MRF run (Fig. 3). CUM_G allows more grid-resolved 
precipitation (Grell 1995). SST_C simulates the largest precipitation (especially during the RI, Fig. 3). In comparison to the CTL, PBL_MRF and CUM_G tend to simulate more precipitation outside the eye wall, especially in the area southwest of the center during the RI. SST_C simulates overall higher precipitation. After the RI, large precipitation area moves to the east or southeast of the center in CUM_G and SST_C, while it still shows large precipitation at the west in PBL_MRF. SST_U has the smallest difference with CTL.

\subsection{Comparisons between model-simulated and QuikSCAT-derived wind fields}

QuickSCAT-derived and model-simulated wind fields during the three days (phases) are given in Figs. 4 and 5, respectively. QuikSCAT passes over the SCS twice a day (descending and ascending passes), with different spatial coverage of the SCS. We choose the pass when QuikSCAT has the best coverage of the TC process for that day and compare with the simulations at the closest hour. Figure 4 clearly shows the evolution of the TC in the SCS. The wind derived from QuikSCAT is stronger at the inner core than that simulated by the model, especially before and during the RI period. Before the RI, the wind patterns from the five experiments are similar, with slight difference in maximum wind speed. During the RI, PBL_MRF simulates relatively smaller maximum wind speed than the other model runs, but has larger range of medium wind speed $(20-25 \mathrm{~m} / \mathrm{s})$. SST_U has the weakest wind, including maximum and medium wind speeds. After the RI, maximum wind speed increases significantly in SST_C. Compared to PBL_MRF and CUM_G, the three experiments of CTL, SST_C, and SST_U simulate a more compact storm structure during the RI.

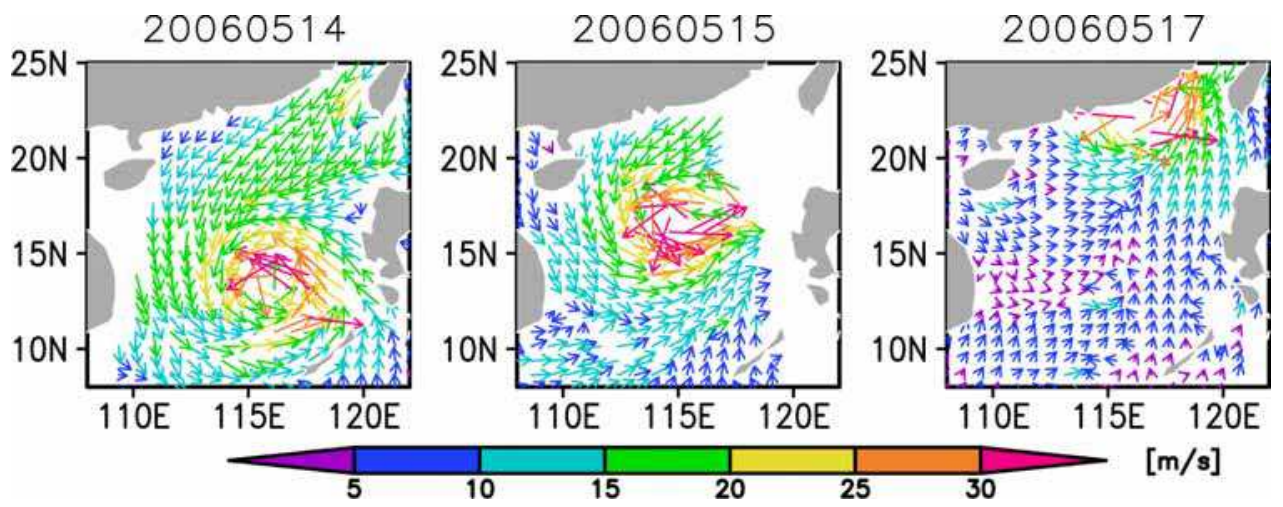

Fig. 4. Wind field derived from QuikSCAT during the three days.

Different atmospheric conditions in PBL_MRF (boundary condition) and CUM_G (cumulus scheme) could cause an increase in latent heat flux and precipitation, but not in storm intensity, such as maximum wind speed and center pressure. However, a warmer SST (in SST_C) could result in an increase in storm intensity in addition to the increase in latent heat flux and precipitation.

\subsection{Conclusions and discussions}

Model simulated precipitation and wind speed are compared with satellite data, in order to evaluate model performance and to test model sensitivity to several parameters that may impact simulation results. Atmospheric boundary condition, cumulus scheme and SST 
distribution can have different influences on rainfall and wind patten during different periods of a TC process. All five model runs in this study overestimate precipitation and underestimate maximum wind speed during Chanchu (2006). Large rainfall area mainly occurs on the west or northwest side of the rainfall center. Areas around rainfall and maximum wind center are chosen to quantify the difference between model simulation and satellite observation. The model configured with Blakadar PBL, Resiner2 moisture, the BM cumulus scheme and daily-updated SST has the best simulation of precipitation. Using the MRF PBL scheme would greatly reduce TC's intensity, which can be clearly reflected in the simulation of maximum wind speed. Constant SST through the TC life cycle provides more energy to the TC, which could cause a significant increase in TC's intensity, therefore leading to the largest overestimation on rainfall and maximum wind. Longitudinallyuniform SST distribution before the RI would reduce TC's intensity and heat flux due to less energy from the ocean.

\section{Bay of Bengal: cluster analysis of tropical cyclone tracks}

\subsection{Introduction}

The Indian sub-continent is one of the worst areas in the world affected by Tropical Cyclones (TCs), although TCs in this region just account for about 7\% of the total number of global TCs (Gray 1968). Unlike TCs in the western Pacific mainly occurring after the monsoon onset, TCs in the Bay of Bengal (BOB) have two seasons. The primary season is during the post-monsoon period and the second one is the pre-monsoon season (Mohanty 1994). During the monsoon, less TCs or tropical disturbances form because strong tropospheric ventilation produced by the large vertical wind shear inhibits storm development (Groy 1968). Compared with TCs in the Pacific and Atlantic, the TC genesis process in the northern Indian Ocean received little attention probably because of lacking in observations. Kikuchi et al. (2009) indicated that the incipient disturbances are virtually absent in the northern Indian Ocean and the initiation process of tropical depression is expected to be different from those in the Pacific and Atlantic Oceans.

Murty et al. (2000) examined the Effective Oceanic Layer for Cyclogenesis (EOLC) parameter, which was related with the near-surface stratified layer developed due to the spread of low salinity waters under the influence of freshwater influx. They found that EOLC should be considered for indentifying the zones of cyclogenesis and for better prediction of cyclone tracks in BOB. Their results indicated that zones of cyclogenesis and mean-cyclone tracks fairly coincide with the zones of higher EOLC. Notably, research about Cyclone Heat Potential (CHP) in BOB partly explained the cyclone genesis in this ocean basin. Sarma et al. (1990) first revealed the seasonal distribution of CHP. By means of CTD observation data sets collected from five cruises during 1993-1996, Sadhuram et al. (2004) found that high value of CHP coincided with anticyclonic gyre (ACG) and vice versa, which emphasized the importance of gyres in the distribution of CHP on the intensification of cyclones/ depressions. In terms of decadal variability, Singh et al. (2000) have proved that there had been a increase trend in the enhanced cyclogenesis during November and May in BOB which account for the maximum number of severe cyclones over the north Indian Ocean. Ocean responses to TC have also been investigated in BOB, which mainly put concern on the sea surface temperature (SST) change under the passage of TC cases (Sadhram 2004). Inertial oscillations signals forced by TC were captured by time-series measurements from a moored data buoy located in BOB set in September 1997 (ebseph et al. 

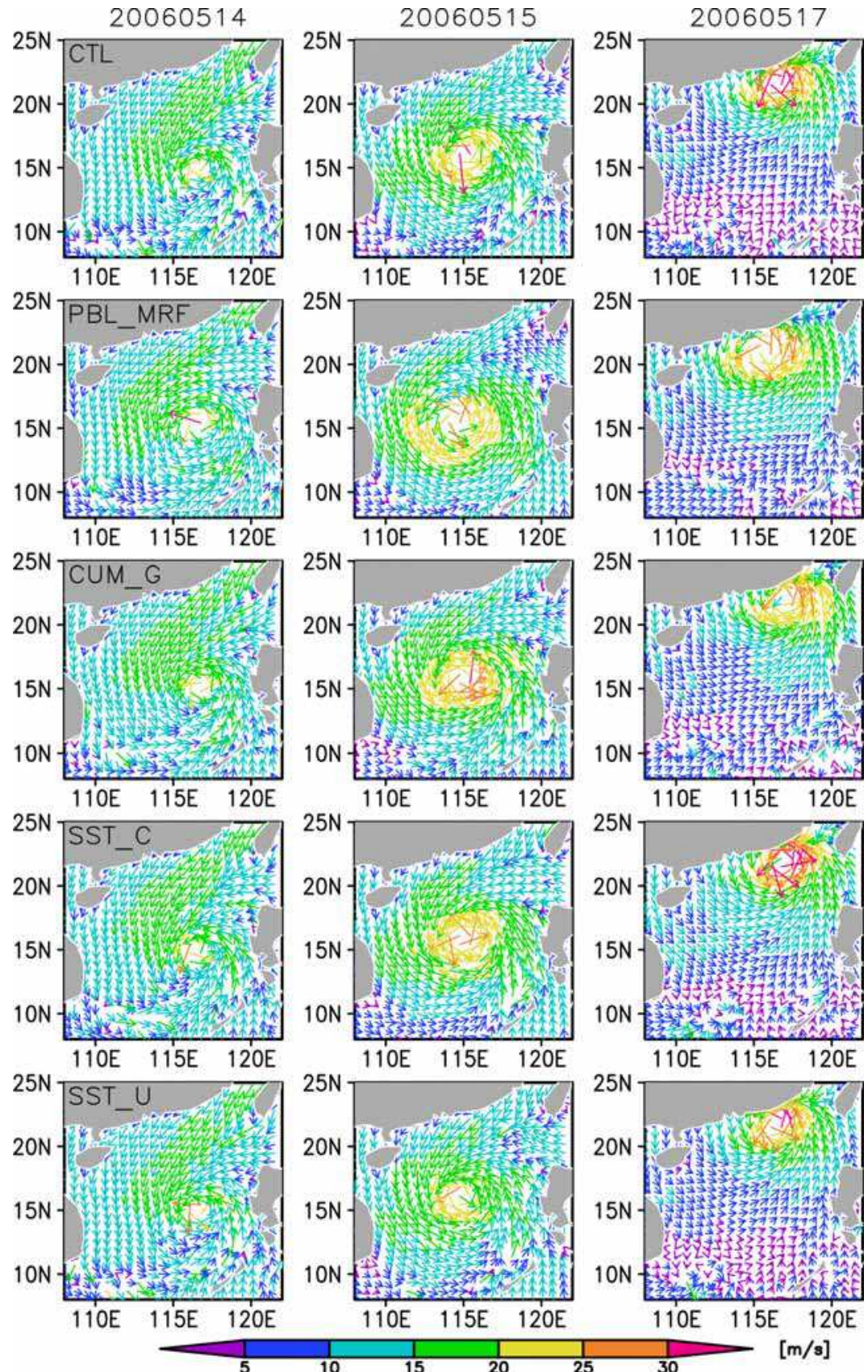

Fig. 5. Wind pattern simulated by the five model runs during the three days. 
2007). Add to the above research, TCs case studies were carried out to find the physical explanations under the specific TC conditions which help improve the operational forecast capability, such as the disastrous TC Nargis in 2008 (Webster 2008; Lin et al. 2009; Kikuchi et al. 2009; Yanase et al. 2010; Yokoi et al. 2010; Yamada et al. 2010; McPhaden et al. 2009).

The TC's track or movement is to be affected by many internal and external factors (Mohanty and Gupta 1997). Steering flow is the prominent external force on TCs, accounting for 70-90\% of the motion. When steering flow is weak, TCs tend to move poleward and westward resulting from the internal force (Chan and Gray 1982; Elsberry et al. 1987). In addition, TCs have a tendency to move tow ard a warmer ocean surface (Orlanski 1998; Mandal et al. 2007). Several methods have been used in sorting tracks, which include $K$-means method (MacQueen 1967). K-means method has been applied in studying North Pacific (Elsner and Liu 2003) and North Atlantic (Elsner 2003) TCs. Nevertheless, $K$-means method cannot accommodate tracks in different lengths. To solve this issue, the finite mixture polynomial regression model (Gaffney 2004) was used to objectively classify the TC tracks, not only based on a few points of trajectory, but on trajectory shape. The technique has been applied to western North Pacific typhoon tracks (Camargo et al. 2007a,b), eastern North Pacific hurricane tracks (Camargo et al. 2008) and the climate modulation of North Atlantic hurricane tracks (Kossin et al. 2010). In recent years, some progresses have been made by using in models for operational track forecast in India, BOB in specific (Mohanty and Gupta 1997; Gupta and Bansal 1997; Prasad and Rao 2003). Sensitive experiments are used to examine the effective factors controlling TC tracks (Mandal et al. 2002, 2003).

These previous studies regarding TC tracks in BOB mainly focused on operational model study. However, objective and systematic analysis about TC tracks in this region remain unknown. Clarifying the physical background of TC tracks in BOB will help to minimize the error of operational forecast for similar TCs in the future, and reduce the loss of lives and properties. Therefore, the focal point of the present study is to show the TC track types classified by results from the mixture regression model, and then depict the seasonal variability and circulation field of each track type.

The study is organized as follows. Datasets used in this study are given in Section 2). Characteristic of track types is described in Section 3). Section 4) shows the seasonal variability, which help further sort tracks. Environmental flow is given in section 5).

\subsection{Data and methods}

TC data is derived from the Joint Typhoon TC tracks (JIWC) for the time interval 1980-2009. The year 1980 is chosen because TC data is more reliable and man-made satellites had already been launched and used for TC observation and forecast since 1980 in BOB. In this study, only TCs with landfall are included in our analysis, for the purpose of examining the environmental flows effectively.

TC track types are detected by a mixture of polynomial regression models which was developed by Gaffney et al. (2004). Compared with the previous cluster analysis methods, this model can fit the geographical "shape" of the trajectories which also allow quadratic function by extending the standard multivariate finite mixture model. Maximizing the likelihood of the parameters helps to find the best fitting mean curve. This method can easily accommodate TC tracks with different length.

Variables from the National Centers for Environmental Prediction/ National Centers for Atmospheric Research (NCEP/ NCAR) reanalysis (Kalnay et al. 1996) since 1980 are used to analyze the background flows of each type of tracks. The entire data records in each case contribute to the composition of their associated track type. 


\subsection{Characteristics of track types}

Under this mixture of polynomial regression models, as measure of goodness of fit, loglikelihood and within-cluster error values are used to obtain the optical mean regression trajectories (track types) of the observed tracks. Within-cluster error is defined as difference in latitude and longitude from the mean regression trajectories squared and summed over all tracks in the cluster for different cluster numbers (Camargo et al. 2007). Fig. 6 shows the log-likelihood values and within-cluster error for different number of clusters on different regression order. Larger log-likelihood with smaller within-cluster error indicates good fit. Here, we choose $K=6$ and quadratic regression order to sort tracks into six types. Fig. 7 shows the historical tracks from 1980 to 2009 of each cluster. They are (1) northeastward with recurvature; (2) westward at lower latitude; (3) longest westward; (4) longer northwestward; (5) shorter northwestward; and (6) northward.

To better find the physical relationship between TC activity and seasonal variation, all westw ard cases (cluster $2,3,4,5$ ) are merged into one category - here as "westward type". Hence, three new track types are listed below: westward (68 cases), northward (31 cases), and northeastward (11 cases) (Fig. 8).

\subsection{Seasonal variability}

Fig. 9a shows the seasonal variability which indicates total TC count during year 1980-2009. Fig. $9 \mathrm{~b}$ gives the contribution of each cluster in each month to the total number of TCs for each cluster during 1980-2009. It shows that westward type have the largest number of cases. Most of these TCs (over 85\%) occurred after winter monsoon onset (September to January), with a peak in October (over 30\%). Northward type has two seasons. The primary season is after October which is similar as the westward type (but delayed for one month), and the second one is pre-summer-monsoon season (April and May). TC numbers in these two seasons are closed. Main peak took place in May, and sub-peak in November (also with one month lag compared to westward type). The northeastward type with recurvature and landing at Myanmar is unique, not only for its fewest number (only 11 cases) but for the two peaks in April and May, which implicit that connection to summer monsoon onset may be considered.

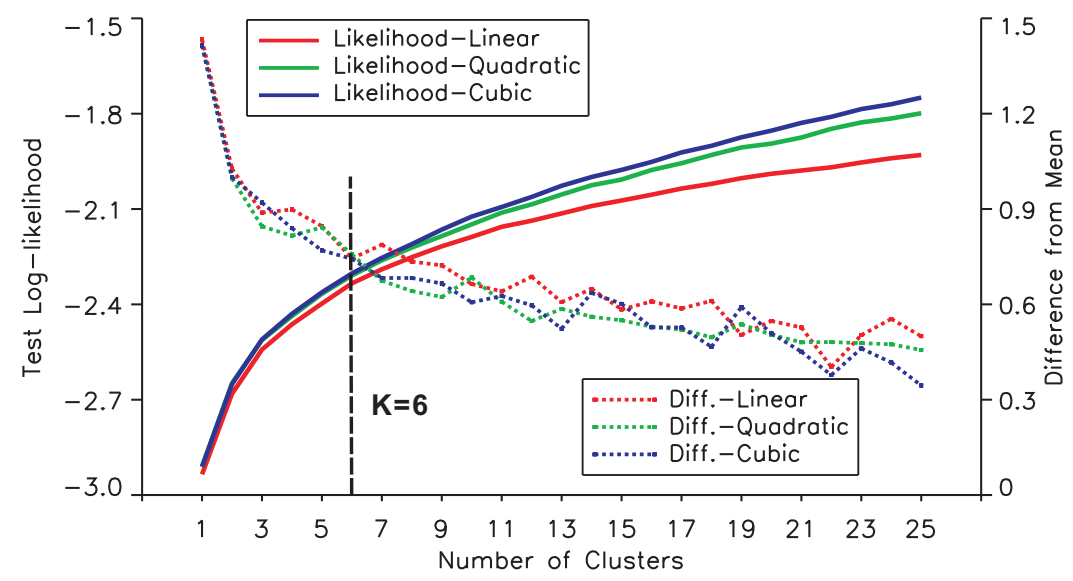

Fig. 6. Log-likelihood values and within-cluster error for different number of clusters on different regression order. 

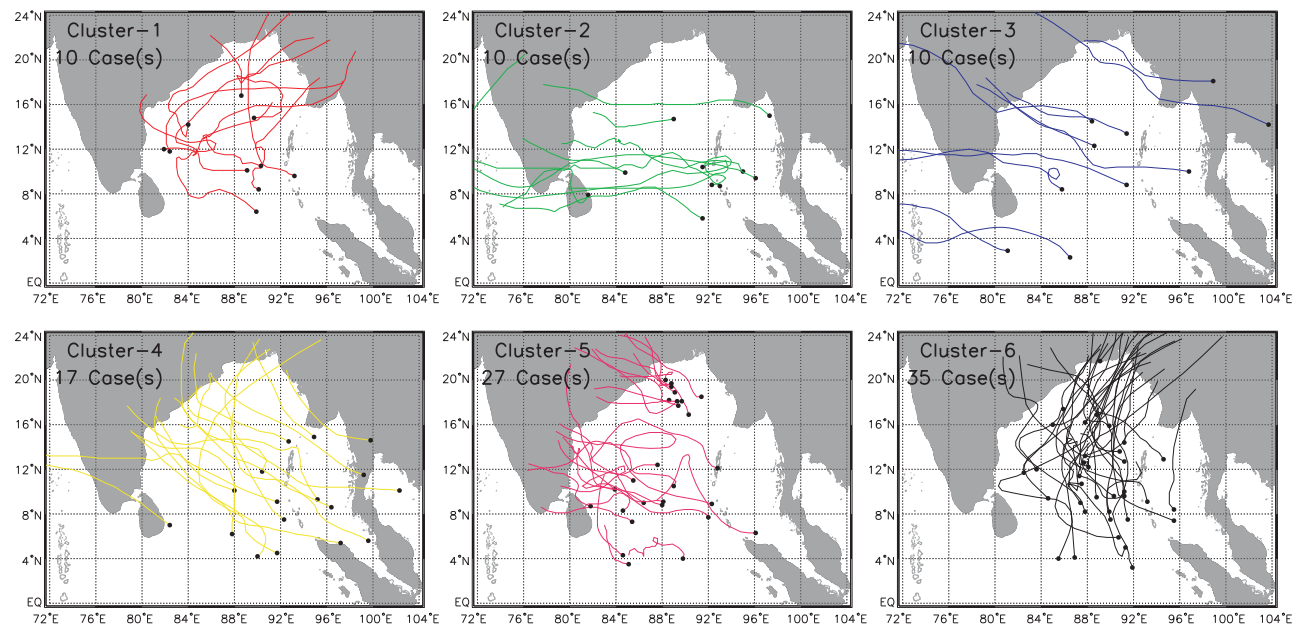

Fig. 7. Historical tracks from 1980 to 2009 of each of the six clusters.
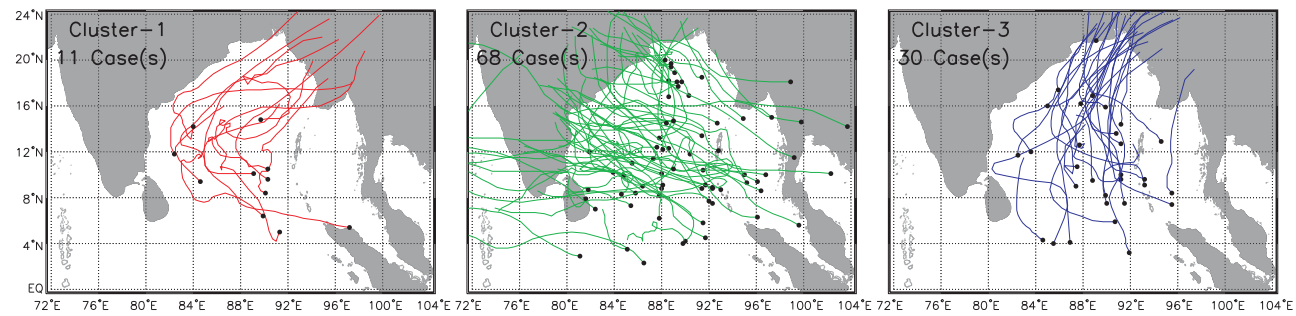

Fig. 8. Historical tracks from 1980 to 2009 of each of the three clusters after reclassifying.
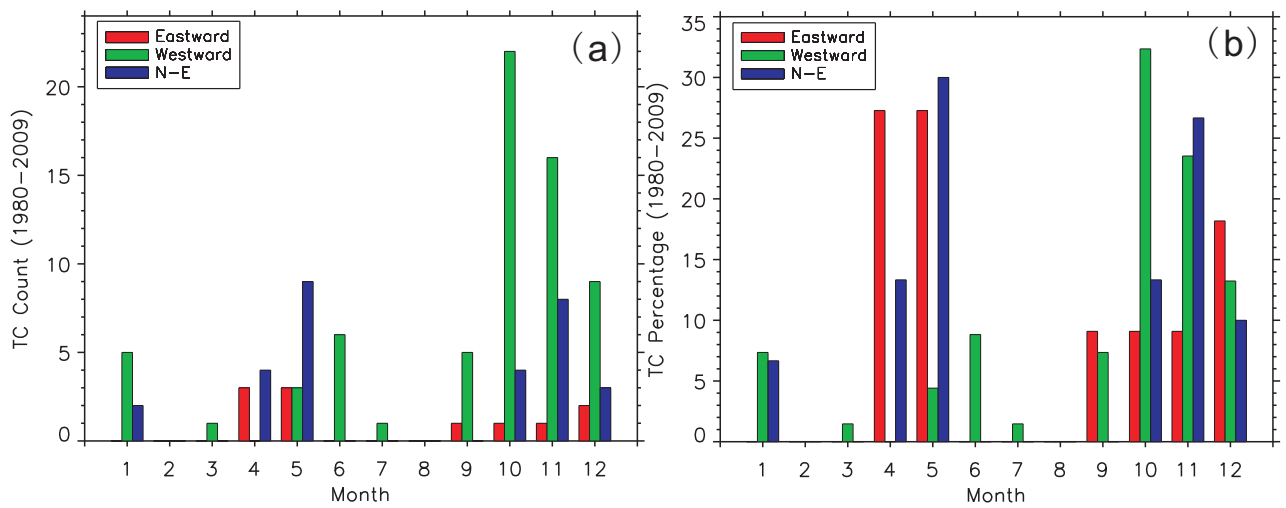

Fig. 9. Seasonal variability of (a) total TC count of year 1980-2009, (b) contribution of each cluster in each month to the total number of TCs for each cluster from 1980-2009 


\subsection{Environmental flow}

Based on the seasonal variability discussed above, northward tracks are divided into two kinds, the one during pre-summer-monsoon (April and May) and the other during postwinter-monsoon (October to January). Figs. 10-13 show the daily vertical wind composition $(600-100 \mathrm{hPa})$ for TCs in each cluster, which composites on all days during the lifecycle of each TC. Demonstration of each track type in detail is given below:

Northeastward: Southerly appeared under $500 \mathrm{hPa}$ across large area, which seemed to be the low level cross-equatorial-flow. Above $500 \mathrm{hPa}$, an anticyclonic circulation occupied IndoChina Peninsular. This system became stronger with height.

Westward: Easterly spread over wide region from northern to middle part of BOB and extend to the Arab Sea. A significant unclosed long and narrow anticyclonic circulation appeared in Indo-China Peninsular which also extended to the Arab Sea. This circulation pattern which also became stronger with height may be associated with the extension of West Pacific Subtropical High.

Northward (April and May): Remarkable southerly also appeared under 500hPa which was similar to the northeastward type. Nevertheless, this channel of wind was limited to the east of $90 \mathrm{E}$ (east $\mathrm{BOB})$, mainly due to northward invasion of the cross-equatorial-flow and southward meander of the northerly in north BOB. These two channels of flow with different properties induced a trough. This trough should belong to the India-Burma Trough which is one of the most frequent-occurring and significant synoptic systems during the premonsoon season. Above $500 \mathrm{hPa}$, the anticyclonic circulation still occupied Indo-China Peninsular which is weaker than the one of westward track type.

Northward (October-January): Anticyclonic circulation in Indo-China Peninsular also appeared which is similar to the westward track type but stronger. Difference is easterly could not extend to India let alone the Arab Sea. It is mainly owing to the trough activity in north India, which can constrain such anticyclone system west invasion. Compared with northward tracks in April and May, the one of this post-winter-monsoon season mostly took place in the western part of BOB.

\subsection{Conclusion and discussion}

By using the mixture quadratic regression model, six clusters of TC tracks in BOB are classified. To better analysis the background physical factors which can affect TC tracks of this region, all westward tracks are sorted as one type. Thereafter, three track types are obtained, northeastward, westward, and northward. After combining the analysis of seasonal variability, it is found that westward TCs which mainly occurred in the postwinter-monsoon period (September-January) were largest in amount. Northward TC were in the next place in amount. Whereas, this type of TCs should be divided by two stages (April-May and October-January), which is more suitable for examining the background controlling systems. Northeastward tracks were fewest in amount. However, this type of TCs generally took place in April and May.

The analysis of background circulation of each track type indicates that except for the northeastward one, anticyclonic circulation located in Indo-China Peninsular as well as the trough activity across the region of India-Burma played important roles on local wind pattern which assisted steering TCs. In addition, TCs happened in April and May (presummer-monsoon), were generally affected by the cross-equatorial-flow and prone to be with northward motion. 


\section{Northeastward}

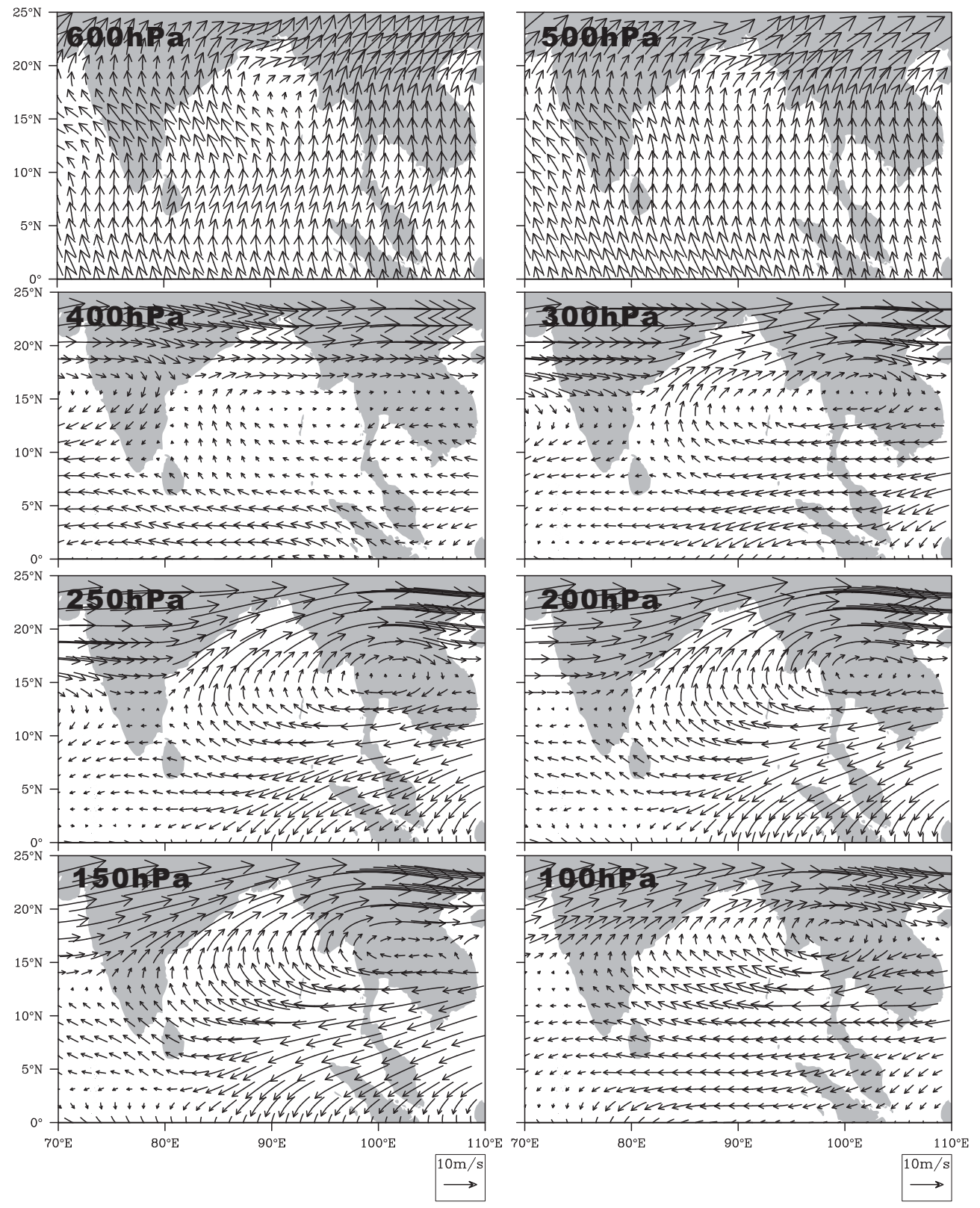

Fig. 10. Daily wind composition $(600-100 \mathrm{hPa})$ for TCs with northeastward tracks, which composites on all days during the lifecycle of each TC. 


\section{Westward}

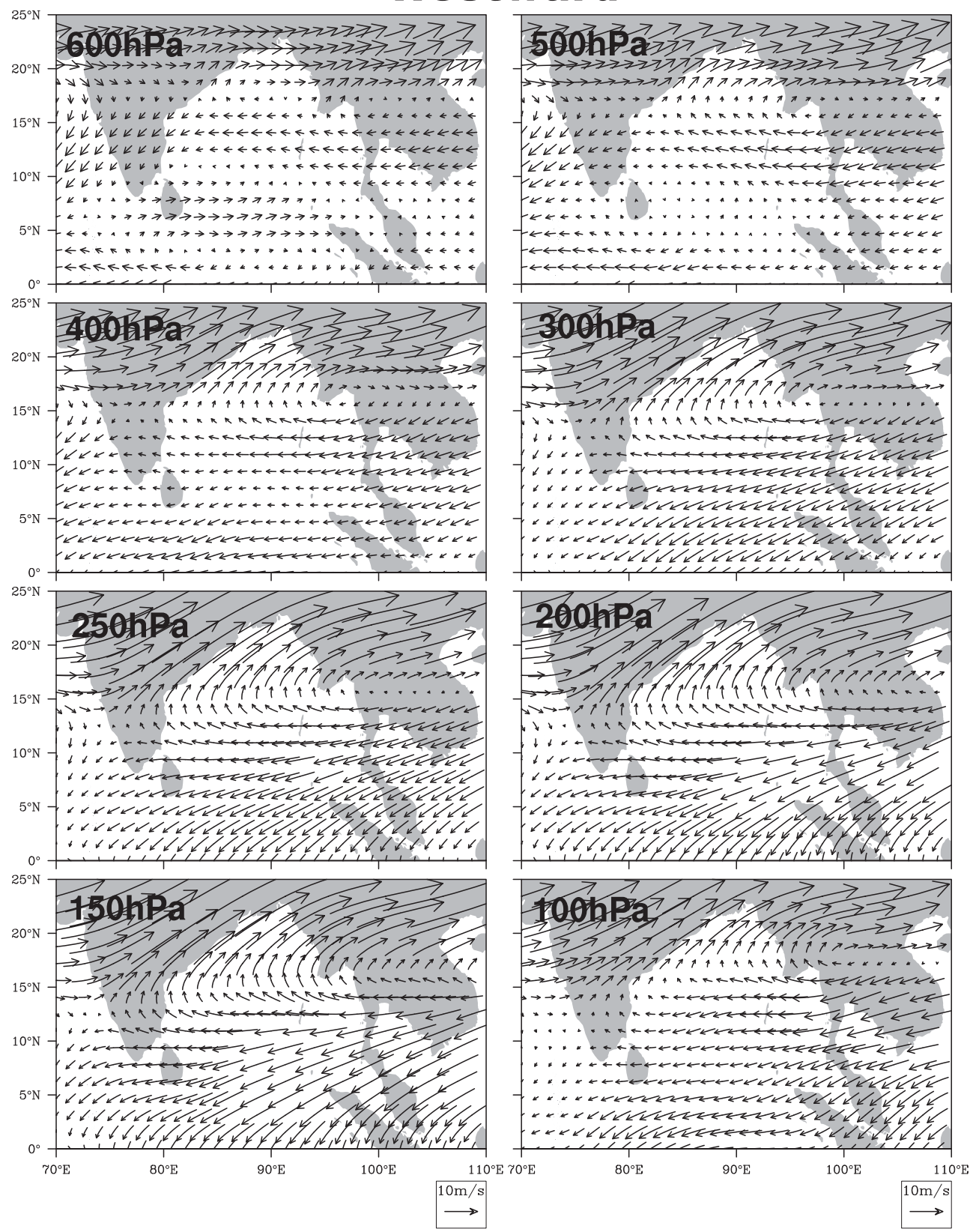

Fig. 11. Same as Fig. 10 but for westward track type. 


\section{Northward Apr \& May}

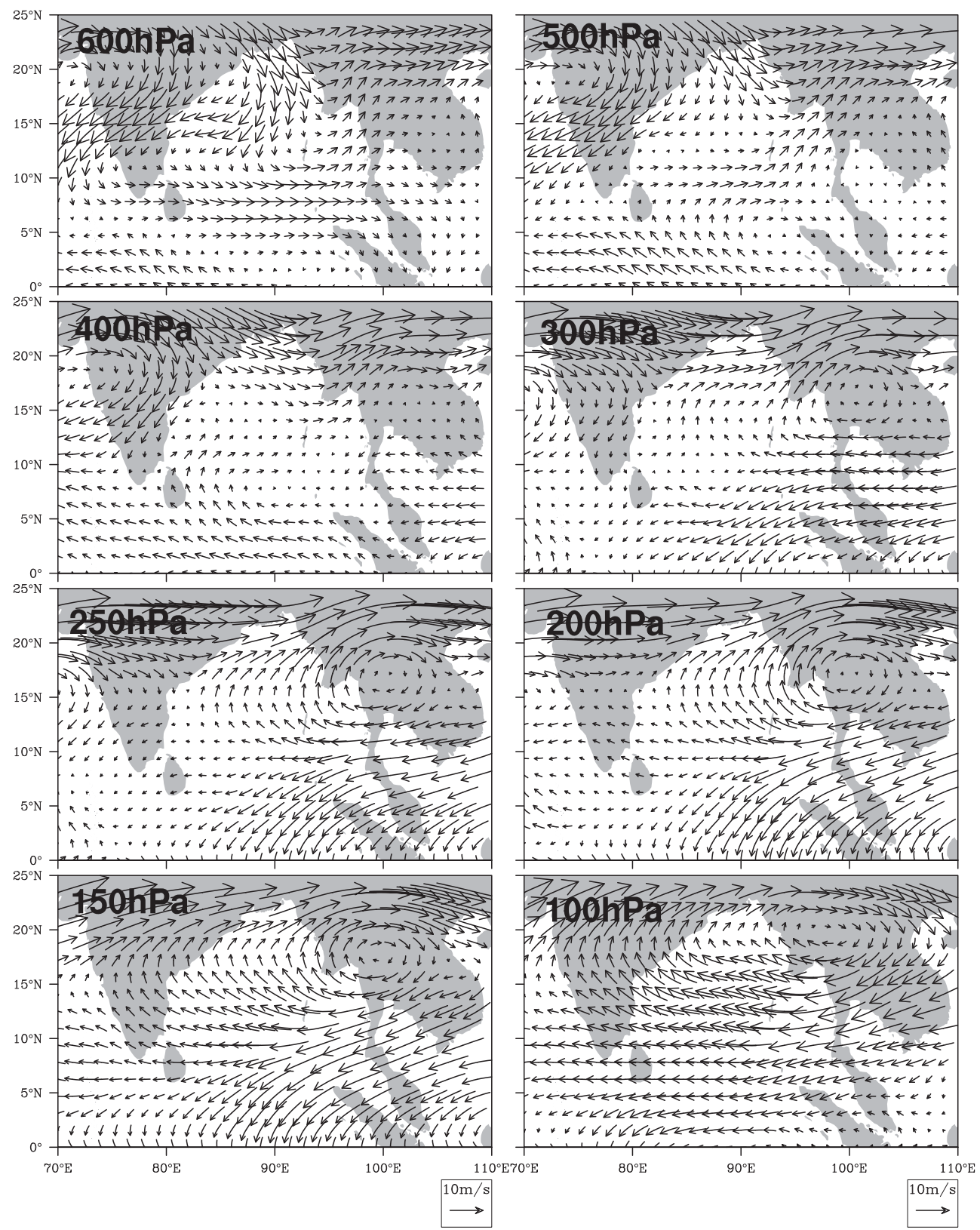

Fig. 12. Same as Fig. 10 but for northward track type in April and May. 


\section{Northward Oct-Jan}
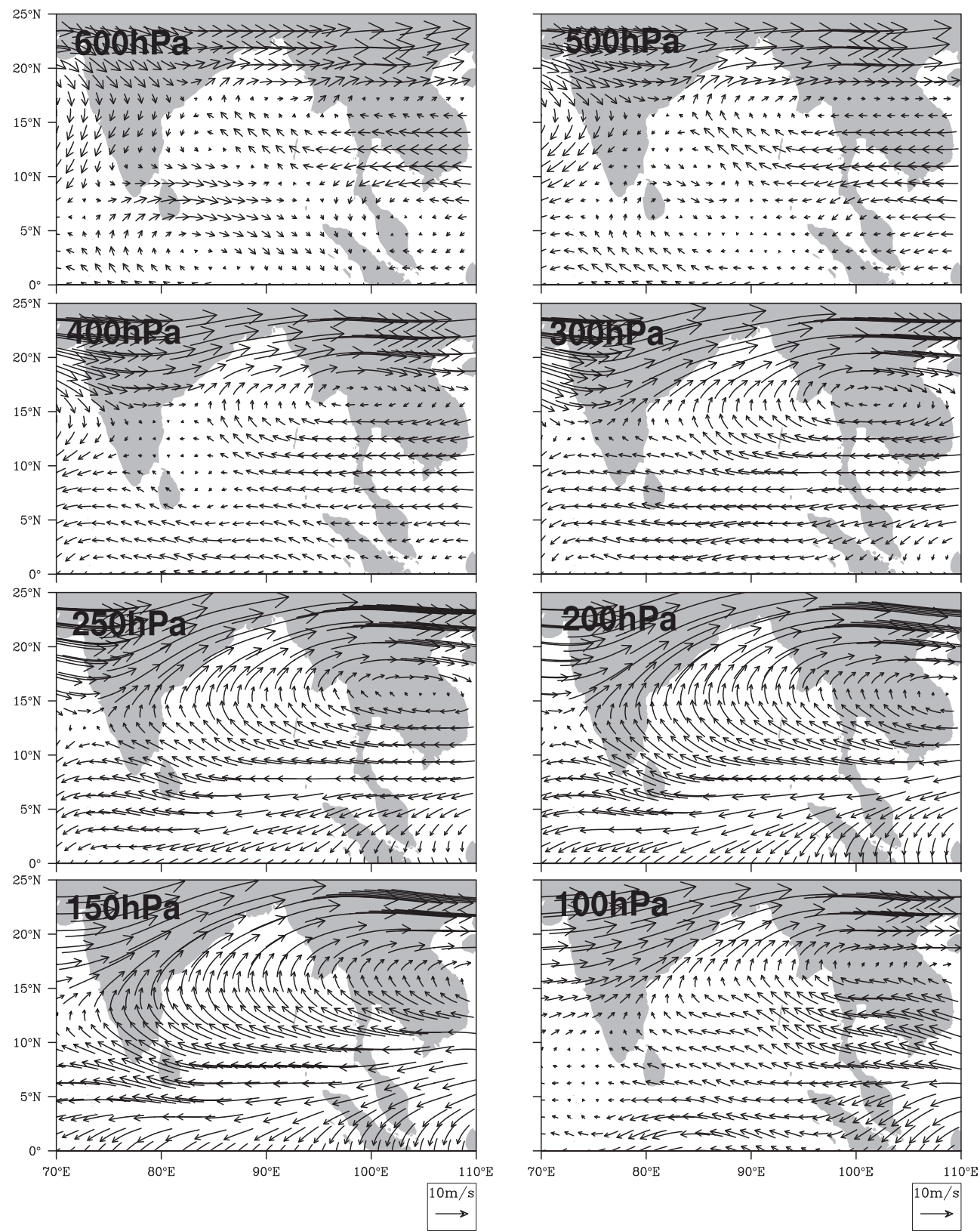

Fig. 13. Same as Fig. 10 but for northw ard track type from October to January. 
The wind fields display the corresponding circulation flow and potential effective local weather systems. In this study, the West Pacific Subtropical High of winter-time may be the critical modulator of TC tracks in this region, specifically during post-winter-monsoon period. Moreover, such strong weather system is associated with Northeast Trade Wind and East Asia Winter Monsoon. How westward this system extends is partly result in whether TC in BOB moves westward or not. Thus, mechanism and causal relationship between the West Pacific Subtropical High as well as possible modulated systems will be investigated in the future.

\section{Acknowledgments}

This research was supported by National 973 projects (No. 2011CB403505), the Natural Science Foundation of China (Grants U0733002), Natural Science Foundation Guangdong, China (Team Research Project 8351030101000002), and the Postdoctoral Fund of China (No. 20090450911).

\section{Reference}

Camargo, S. J., A. W. Robertson, S. J. Gaffney, P. Smyth, and M. Ghil, 2007: Cluster analysis of typhoon tracks. Part I: General properties. I Climate, 20, 3635-3653.

A. W. Robertson, S. J. Gaffney, P. Smyth, and M. Ghil, 2007: Cluster analysis of typhoon tracks. Part II: Large-Scale Circulation and ENSO. .J Climate, 20, 3654-3676.

A. W. Robertson, A.G. Barnston, and M. Ghil, 2008: Clustering of eastern North Pacific tropical cyclone tracks: ENSO and MJO effects, Geochemistry, Geophysics and Geosystems, 9, Q06v05.

Chan, J. C. L. and W.M. Gray, 1982: Tropical cyclone movement and surrounding flow relationships, Mon. Wea. Rev., 110, 1354-1374.

Chen, L. S. and Y. H. Ding, 1979: An Introduction to the West Pacific Ocean Typhoons, Science Press, Beijing, China, pp. 400-490 (In Chinese).

Chou, S.-H., Nelkin, E., Ardizzone, J., Atlas, R. M. and Shie, C.-L., 2003: Surface turbulent heat and momentum fluxes over global oceans based on the Goddard satellite retrievals version2 (GSSTF2). el Clim., 16, 3256-3273.

Elsberry, R. L., W. M. Frank, G. J. Holland, J. D. Jarrell, and R. L. Southern, 1987: A global view of tropical cyclones, Univ. Chicago Press, $185 \mathrm{pp}$.

Gaffney, S. J., 2004: Probabilistic curve-aligned clustering and prediction with regression mixture models. Ph.D. thesis, University of California, Irvine, 281.

Goh, A. Z., and J. C. L. Chan, 2009: Interannual and interdecadal variations of tropical cyclone activity in the South China Sea, Int.el Climtaolo., doi:10.1002/ joc.1943.

Grell, G. A., J Dudhia, and F. R. Stauffer, 1995: A description of the fifth-generation Penn State/ NCAR Mesoscale Model (MM5). NCAR Tech. Note NCAR/TN-398 +STR, $122 \mathrm{pp}$.

Gray, W. M., 1968: Global view of the origin of tropical disturbances and storms, Mon. Wea. Rev., 96, 669-700.

Gupta, A., R. K. Bansal, 1997: Performance of a global spectral model in predicting the track of a hurricane in the Bay of Bengal using synoptic vortex, NCMRWF, New Delhi Tech. report.

Jiang, X.-P., Z. Zhong, and C.-X. Liu, 2006: The effect of typhoon-induced SST cooling on typhoon intensity: the case of typhoon Chanchu (2006). Adv. Atmos. Sci., 25 (6), 1062-1072. 
Joseph, K. J., A. N. Balchand, P.V. Hareeshkumar, and G. Rajesh, 2007: Inertial oscillation forced by the September 1997 cyclone in the Bay of Bengal, Current Sci., 92, 790-794.

Kikuchi, K., B. Wang, and H. Fudeyasu, 2009: Genesis of tropical cyclone Nargis revealed by multiple satellite observations, Geophys. Res. Lett., 36, L06811, doi:10.1029/ 2009GL037296, 2009.

Kossin, J. P., S. J. Camargo, M. Sitkowski, 2010: Climate Modulation of North Atlantic Hurricane Tracks. el Climate, 23, 3057-3076.

Langland, R. H., C. Velden., P. M. Pauley and others, 2009: Impact of Satellite-Derived Rapid-Scan Wind Observations on Numerical Model Forecasts of Hurricane Katrina. Mon Wea Rev., 137, 1615-1622.

Lau, K-H., Z. Zhang, H. Lam and others, 2003. Numerical simulation of a South China Sea typhoon Leo (1999), Meteoro Atmos Phys., 83, 147-161.

Lee, C. S., Y. L. Lin, and K. K.W. Cheung, 2006: Tropical cyclone formations in the South China Sea associated with the Mei-Yu front, Mon. Wea. Rev., 134, 2670-2687.

Li, J., A. Wang, E. Hou, G. Li, X. He, T. Peng, and Q. Zeng, 2004: A numerical prediction experiment of track and heavy rainfall about Typhoon Fitow. I Tropical Oceanog., 23 (1) (In chinese).

Li Q., Y. Duan, H. Yu and others, 2008, A High-Resolution Simulation of Typhoon Rananim (2004) with MM5, Part I: Model Verification, Inner-Core Shear, and Asymmetric Convection, Mon Wea Rev, 136(7), 2488-2506.

Liang, B. Q., 1991: Tropical atmospheric circulation system over the South China Sea, China Meteorology Press, Beijing, China, Pp. 100-224 (In Chinese).

Lin, I.- I., C.- H. Chen, I.- F. Pun, W. T. Liu, and C.-C. Wu, 2009: Warm ocean anomaly, air sea fluxes, and the rapid intensifi cation of tropical cyclone Nargis (2008), Geophys. Res. Lett., 36, L03817, doi:10.1029/ 2008GL035815, 2009

Liu, X. G. Jiang, and H. Zhuo, 2009: Numerical experiment for the impact of SST to Typhoon Chanchu. Marine Forecasts, 26(3), 1-10. (In Chinese)

Luo, B., C. Zhang, M. Huang, Y. Li, and L. Li, 2008: The analysis of 0601 strong typhoon 'Chanchu, Marine Forecasts, 25(1), 95-101. (In Chinese)

Mandal, M., U.C. Mohanty, P. Sinha, and M.M.Ali, 2007: Impact of sea surface temperature in modulating movement and intensity of tropical cyclones, Nat. Hazards, 41, 413427.

—, U.C. Mohanty, K.V.J. Potty, and A. Sarkar, 2003: Impact of horizontal resolution on prediction of tropical cyclones over Bay of Bengal using a regional weather prediction model, Proc. Indian Acad. Sci. (Earth Planet. Sci.), 112, 79-93.

— U.C. Mohanty, S.Raman, 2002: A Study on the Impact of Parameterization of Physical Processes on Prediction of Tropical Cyclones over the Bay of Bengal with NCAR/ PSU Mesoscale Model, Nat. Hazards, 31, 391-414.

McPhaden, M. J., G. R. Foltz, T. Lee, V. S. N. Murty, M. Ravichandran, G. A. Vecchi, J. Vialard, J. D. Wiggert, and L. Yu, 2009: Ocean-Atmosphere Interactions During Cyclone Nargis, EOS, 90(7), 53-60.

Mohanty, U.C., 1994: Tropical cyclones in the Bay of Bengal and deterministic methods for prediction of their trajectories, Sadhana, 19, 567-582.

— and A. Gupta, 1997: Deterministic methods for prediction of tropical cyclone tracks, Mausam, 48, 257-272.

Murty, V.S.N, M.S.S. Sarma, and V. Tilvi, 2000: Seasonal cyclogenesis and the role of nearsurface stratified layer in the Bay of Bengal, PORSEC Proceedings, 1, 453-457. 
Nolan, D. S., J. Zhang, and D. P. Stern, 2003: Evaluation of Planetary Boundary Layer Parameterizations in Tropical Cyclones by Comparison of In Situ Observations and High-Resolution Simulations of Hurricane Isabel (2003), Part I: Initialization, Maximum Winds, and the Outer-Core Boundary Layer, Mon Wea Rev., 137 (11): 3651-3674.

Orlanski, I., 1998: Polew ard deflection of storm tracks, el Atmos. Sci., 55, 2577-2602.

Prasad, K. and Y. V. Rama Rao, 2003: Cyclone Track prediction by a quasi-Lagrangian model, Meteor. Atmos. Phys., 83,173-185.

Rakesh, V., R. Singh, P. K. Pal and others, 2009: Impacts of Satellite-Observed Winds and Total Precipitable Water on WRF Short-Range Forecasts over the Indian Region during the 2006 Summer Monsoon, Wea. Forecast, 24, 1706-1731.

Sarma, Y.V.B, V.S.B. Murty, and D.P. Rao, 1990: Distribution of cyclone heat potential in the Bay of Bengal, Indian el of Marian Sci., 19, 102-106.

Sadhuram, Y., B.P. Rao, D.P. Rao, P.N.M. Shastri, and M.V. Subrahmanyam, 2004, Nature Hazards, 32, 191-209.

, 2004, Current Sci., 86, 383-384.

Singh, O.P., Tariq Masood Ali Khan, and Md. Sazedur Rahman, 2000: Has the frequency of intense tropical cyclones increased in the north Indian Ocean?, Current Sci., 80, 575580.

Soden, B. J., C. S. Velden, and R. E. Tuleya, 2001: The Impact of Satellite Winds on Experimental GFDL Hurricane Model Forecasts, Mon Wea Rev.,129, 835-852.

Wang, G., J. Su, Y. Ding, and D. Chen, 2007, Tropical cyclone genesis over the South China Sea, cl Marine Sys., 68, 318-326.

Wang, L. K-H. Lau, and C-H. Fung, 2010: Numerical simulation of the genesis of Typhoon Durian (2001) over the South China Sea: the effect of sea surface temperature, $I$ Ocean Univ. China, 99-115.

Wang, L., K-H. Lau, C-H. Fung, and JP. Gan, 2007: The relative vorticity of ocean surface winds from the QuikSCAT satellite and its effects on the geneses of tropical cyclones in the South China Sea, Tellus, 59A, 562-569.

Weber, H. C., 2001: Hurricane Track Prediction with a New Barotropic Model, Mon. Wea. Rev., 129, 1834-1858.

Yanase, W., H. Taniguchi, and M. Satoh: 2010: The genesis of tropical cyclone Nargis (2008): environmental modulation and numerical predictability, II Meteor. Soc. elapan, 88, 497-519.

Yamada, H., Q. Moteki, and M. Yoshizaki, 2010: The unusual track and rapid intensification of cyclone Nargis in 2008 under a characteristic environmental flow over the Bay of Bengal, J. Meteor. Soc. elopan, 88, 437-453.

Yokoi, S., and Y. N. Takayabu, 2010: Environmental and external factors in the genesis of tropical cyclone Nargis in April 2008 over the Bay of Bengal, el Meteor. Soc. elpan, 88, 425-435.

Zeng, L.-L., P. Shi, W. T. Liu, and D. Wang, 2008: Evaluation of a satellite-derived latent heat flux product in the South China Sea: A comparison with moored buoy data and various products. Atmos. Res., 94 (1), doi:10.16/ j.atmosres.2008.12.007.

Zhao, Y., B. Wang, Z.J., X. Liang, G. Deng, and X. Zhang, 2005: Improved track forecasting of a typhoon reaching landfall from four-dimensional variational data assimulation of AMSU-A retrieved data, el Geophys. Res., 110, D14101, doi:10.1029/ 2004JD005267.

Zou, X., and Q. Xiao, 2000: Studies on the initialization and simulation of a mature hurricane using a variational bogus data assimilation scheme. el Atmos. Sci., 57, 836-860. 


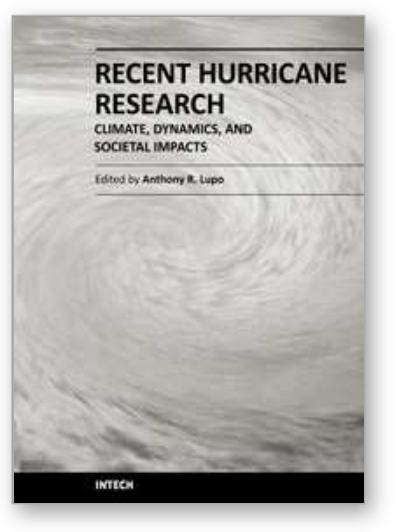

\author{
Recent Hurricane Research - Climate, Dynamics, and Societal \\ Impacts \\ Edited by Prof. Anthony Lupo
}

ISBN 978-953-307-238-8

Hard cover, 616 pages

Publisher InTech

Published online 19, April, 2011

Published in print edition April, 2011

This book represents recent research on tropical cyclones and their impact, and a wide range of topics are covered. An updated global climatology is presented, including the global occurrence of tropical cyclones and the terrestrial factors that may contribute to the variability and long-term trends in their occurrence. Research also examines long term trends in tropical cyclone occurrences and intensity as related to solar activity, while other research discusses the impact climate change may have on these storms. The dynamics and structure of tropical cyclones are studied, with traditional diagnostics employed to examine these as well as more modern approaches in examining their thermodynamics. The book aptly demonstrates how new research into short-range forecasting of tropical cyclone tracks and intensities using satellite information has led to significant improvements. In looking at societal and ecological risks, and damage assessment, authors investigate the use of technology for anticipating, and later evaluating, the amount of damage that is done to human society, watersheds, and forests by land-falling storms. The economic and ecological vulnerability of coastal regions are also studied and are supported by case studies which examine the potential hazards related to the evacuation of populated areas, including medical facilities. These studies provide decision makers with a potential basis for developing improved evacuation techniques.

\title{
How to reference
}

In order to correctly reference this scholarly work, feel free to copy and paste the following:

Lei Yang, Wei-Wei Li, Dongxiao Wang and Yongping Li (2011). Analysis of Tropical Cyclones in the South China Sea and Bay of Bengal during Monsoon Season, Recent Hurricane Research - Climate, Dynamics, and Societal Impacts, Prof. Anthony Lupo (Ed.), ISBN: 978-953-307-238-8, InTech, Available from: http://www.intechopen.com/books/recent-hurricane-research-climate-dynamics-and-societal-impacts/analysisof-tropical-cyclones-in-the-south-china-sea-and-bay-of-bengal-during-monsoon-season

\section{INTECH}

open science | open minds

\author{
InTech Europe \\ University Campus STeP Ri \\ Slavka Krautzeka 83/A \\ 51000 Rijeka, Croatia \\ Phone: +385 (51) 770447 \\ Fax: +385 (51) 686166
}

\author{
InTech China \\ Unit 405, Office Block, Hotel Equatorial Shanghai \\ No.65, Yan An Road (West), Shanghai, 200040, China \\ 中国上海市延安西路65号上海国际贵都大饭店办公楼405单元 \\ Phone: +86-21-62489820 \\ Fax: $+86-21-62489821$
}


www.intechopen.com 
(C) 2011 The Author(s). Licensee IntechOpen. This chapter is distributed under the terms of the Creative Commons Attribution-NonCommercialShareAlike-3.0 License, which permits use, distribution and reproduction for non-commercial purposes, provided the original is properly cited and derivative works building on this content are distributed under the same license. 